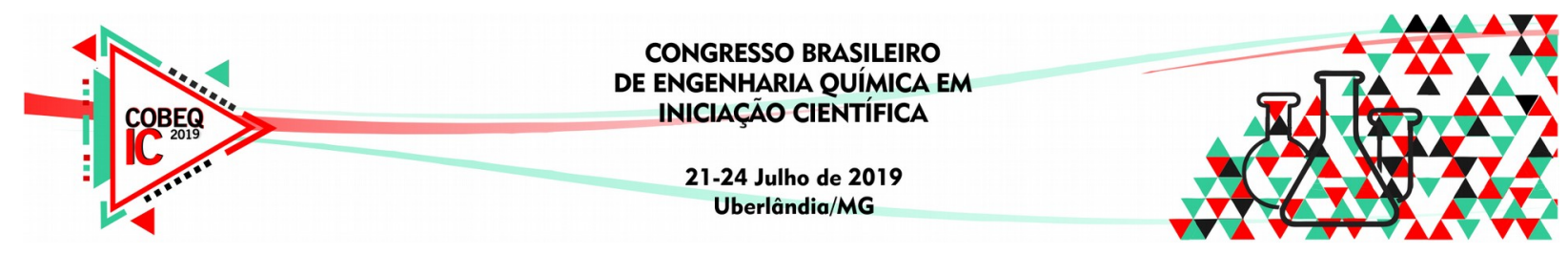

\title{
CARACTERIZAÇÃO E CONCENTRAÇÃO DE GELATINA EXTRAÍDA DE RESÍDUO DE COURO CURTIDO AO CROMO (III)
}

\author{
D. D. C. KREIN ${ }^{1}$, M. ROSSETO ${ }^{2}$, A. DETTMER ${ }^{1}$, B. I. S. DAMIN ${ }^{1}$ \\ ${ }^{1}$ Universidade de Passo Fundo, Faculdade de Engenharia e Arquitetura, Curso de Engenharia \\ Química \\ ${ }^{2}$ Universidade de Passo Fundo, Faculdade de Agronomia e Medicina Veterinária, Programa \\ de Pós Graduação em Ciência e Tecnologia de Alimentos \\ E-mail para contato: kreindaniela@gmail.com
}

\begin{abstract}
RESUMO - Em busca de minimizar o impacto ambiental causado pela disposição de resíduos perigosos industriais em aterros, surgem alternativas para estudar o potencial de determinados resíduos para aplicação em outros processos. O resíduo de couro curtido pode ser utilizado como matéria-prima para extração de gelatina. Para eliminar a presença de sais de curtimento e aqueles oriundos da extração, a gelatina pode ser concentrada através de membranas de ultrafiltração que trabalharam na pressão constante de 1 bar e tamanho de poros de $20 \mathrm{kDa}$. O objetivo do trabalho avaliou a influência das membranas sobre as propriedades da gelatina. Os resultados mostraram que a utilização das membranas promoveu uma concentração no teor nitrogênio total Kjeldahl., além da redução nos teores de cromo, condutividade e cinzas.
\end{abstract}

\section{INTRODUÇÃO}

A indústria do couro é de grande significância para o Brasil, que é reconhecido mundialmente como referência em qualidade de couros e possui o maior rebanho bovino comercial do mundo (CICB, 2019).

O setor é responsável pela geração de grande quantidade de resíduos sólidos, classificados como perigosos pela NBR 10.004 (2004). Sua disposição final geralmente é feita em aterros industriais perigosos (Brandalise, 2017). Contudo, com a demanda do setor coureiro associada com o alto volume de resíduos produzidos, estudos sugerem que este seja reaproveitado como matéria-prima para outros processos. Existem várias possibilidade para minimizar os impactos ambientais que vão desde a recuperação do cromo para produção de ligas metálicas (Fernandez, 2010) até a utilização do resíduo como adsorvente para tratamento de efluentes (Gomes, 2014).

Das muitas alternativas que vêm sendo estudadas para a recuperação e/ou reutilização deste resíduo, se destaca a extração de gelatina do colágeno presente no couro através de hidrólise do material (Scopel, 2018). Por se tratar de uma gelatina obtida de um resíduo de couro curtido, há a presença de muitos sais, como sódio, magnésio e cromo. A remoção desses sais é de extrema importância, pois como são higroscópicos, podem proporcionar ao filme alta absorção de água e este se degradar rapidamente, dificultando sua aplicabilidade. 


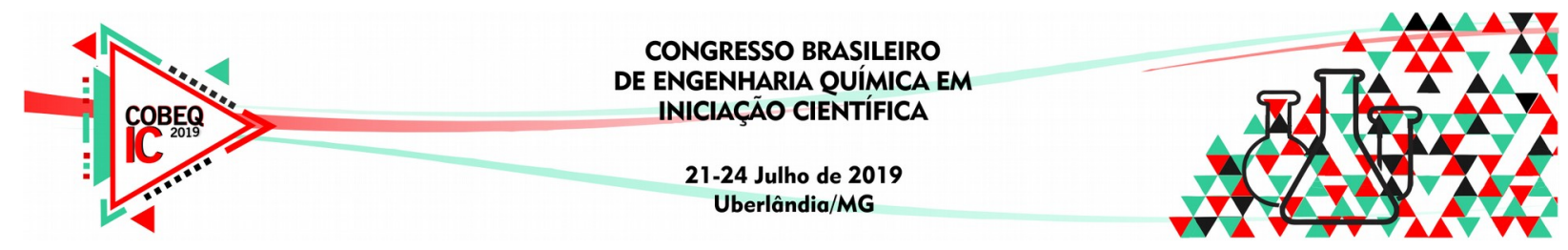

Para utilizar a gelatina como base para a formulação de filmes poliméricos, é necessário remover os sais presentes na sua composição. Logo, a utilização de membranas de ultrafiltração (UF) para concentração de gelatina e retirada dos sais é uma ótima opção. Segundo Wang e Shi (2011), esta tecnologia está em ascensão, pois além de ser uma tecnologia limpa e apresentar baixo custo, proporciona menor degradação da amostra ao longo do processo quando comparado a outras formas de concentração, como a evaporação.

Sendo assim, o objetivo deste trabalho foi avaliar a influência da concentração por membranas de ultrafiltração da gelatina extraída de resíduo de couro curtido ao cromo (RCCC) sobre as propriedades de cromo, cinzas, condutividade e nitrogênio. Para tal, caracterizou-se o resíduo de couro, a gelatina extraída, a gelatina retida (concentrada) e o permeado.

\section{EXPERIMENTAL}

\subsection{Extração da gelatina}

Para a extração da gelatina, $25 \mathrm{~g}$ de resíduo de couro curtido ao cromo (RCCC) foram colocados em um erlenmeyer em solução com $125 \mathrm{~mL}$ de água destilada e $1 \mathrm{~g}$ de óxido de magnésio, como agente alcalinizante. Os recipientes foram dispostos em uma câmara de agitação (shaker), onde ficaram sob agitação de $150 \mathrm{rpm}$ por 6 horas, a $70{ }^{\circ} \mathrm{C}$. Após este período, a solução foi filtrada através de uma bomba de vácuo, de onde se obteve a gelatina, que foi armazenada em geladeira até se obter volume suficiente para uso de membranas e caracterização do material.

\subsection{Concentração de gelatina em membranas de ultrafiltração}

A gelatina extraída foi aquecida a temperatura de $45{ }^{\circ} \mathrm{C}$ para melhor desempenho nas membranas e colocada em um tanque de armazenamento. Utilizou-se uma pressão de 1 bar e uma vazão de $0,0024 \mathrm{~m}^{3} / \mathrm{h}$. A membrana de ultrafiltração utilizada apresenta um tamanho de poros de $20 \mathrm{kDa}$. Para entender o processo de filtração, pode-se observar a Figura 1. Deixouse o conteúdo circular até que todo o volume inicial passasse pela membrana. Obteve-se uma corrente de permeado e outra de gelatina retida nas membranas. 


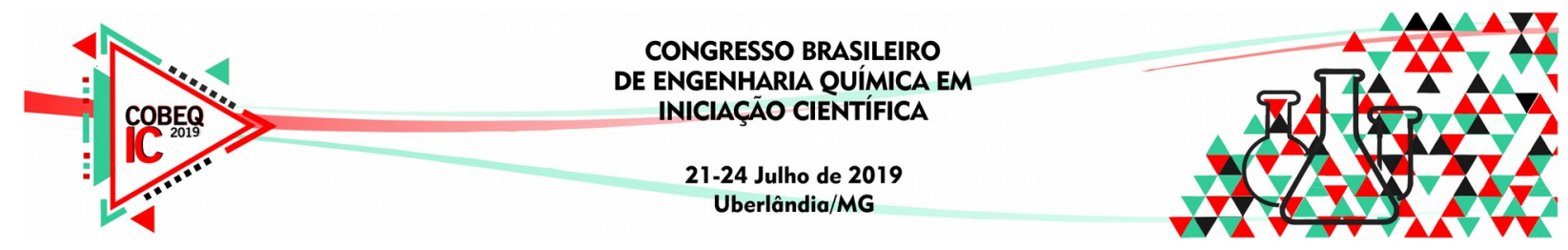

Figura 1 - Processo de concentração de gelatina extraída de resíduo de couro com membranas de ultrafiltração.

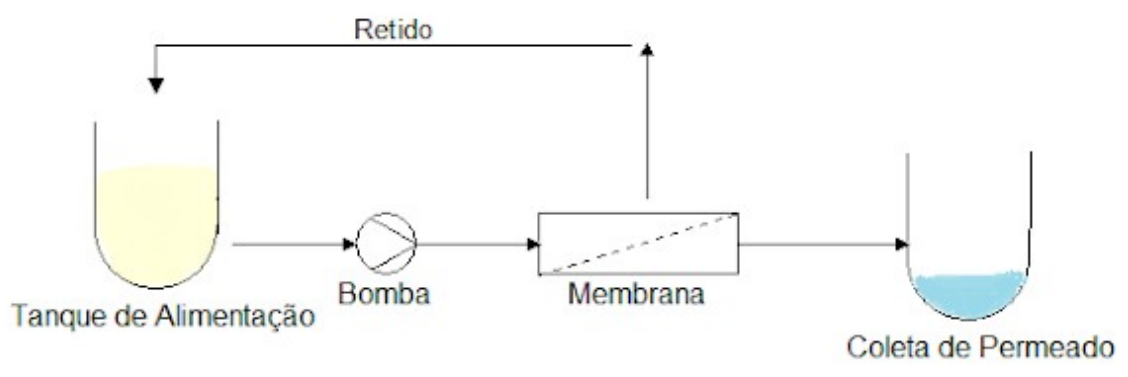

Fonte: Autores, 2019.

Um volume inicial de 4,8 L de gelatina foi adicionada no tanque de alimentação. Uma bomba faz a sucção da gelatina até a membrana, que separará a corrente de alimentação em duas outras: retido e permeado. A corrente de retido é responsável por coletar moléculas maiores que os poros da membrana (moléculas de gelatina), que voltarão para o tanque de alimentação, recirculando mais uma vez pela membrana. Para moléculas menores que os poros da membrana, como sais e água, estas se permeiam através da membrana e são coletadas na corrente de permeado. A filtração foi realizada até se coletar, no mínimo, $75 \%$ do volume inicial de permeado.

\subsection{Caracterização de amostras}

As análises foram realizadas em triplicata para as amostras de resíduo de couro, de gelatina recuperada, gelatina retida e permeado para as seguintes análises:

Umidade: A umidade das amostras foi determinada seguindo o procedimento da norma ASTM D3790-2012, onde pesou-se cerca de 3 a 5 g de amostra em cápsulas de alumínio, que foram levadas à estufa em uma temperatura de $105^{\circ} \mathrm{C}$. As amostras ficaram em estufa até se obter peso constante, para posterior cálculo de umidade.

Cinzas: A identificação da quantidade de cinzas também seguiu o método ASTM D2617-2012. Cerca de 2 a $5 \mathrm{~g}$ das amostras foram incinerados em bico de Bunsen, em cadinhos previamente calcinados e depois colocados em mufla na temperatura de $550^{\circ} \mathrm{C}$ por 4 horas.

pH: A análise das amostras de gelatina e permeado foi realizada em um pHmetro (Digimed, Modelo DM-22), onde $50 \mathrm{~mL}$ de amostra foram submetidas a análise. Para as amostras de resíduo de couro seguiu o método da ASTM D2810-1972, no qual foram utilizadas $2 \mathrm{~g}$ de resíduo de couro em solução com $20 \mathrm{~mL}$ de água destilada em um frasco erlenmeyer que permaneceu sob agitação por 4 horas em temperatura ambiente, para posterior verificação de $\mathrm{pH}$.

Condutividade: A condutividade foi medida apenas nas amostras de gelatina e 


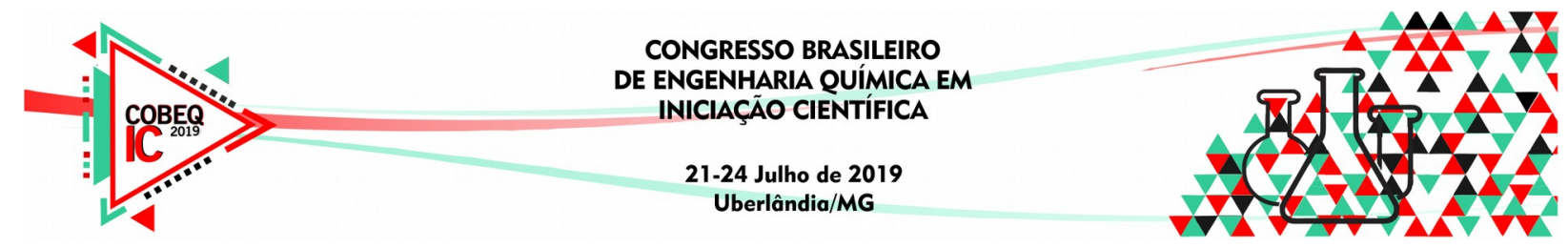

permeado, através de um condutivímetro (Tecnal, Modelo Tec-4MP).

Nitrogênio total kjeldahl: Seguindo o procedimento ASTM D2868-1996, a determinação de Nitrogênio Total Kjeldahl (NTK) se resume nas etapas de digestão, destilação e titulação, onde o ácido sulfúrico concentrado $0,3 \mathrm{M}$ foi utilizado para digestão e titulação, respectivamente, além de ácido bórico para a destilação das amostras, e posterior quantificação de nitrogênio.

Teor de cromo: A determinação de cromo foi realizada por dois métodos diferentes: titulometria para o resíduo de couro e teste com difenil carbazida para as amostras de gelatina e permeado. Pelo método de titulometria, o cromo foi determinado na forma de óxido de cromo (CrO3), utilizando o método ASTM D2807-1993. Ácido nítrico, perclórico e sulfúrico são usados para promover a oxidação do cromo da amostra na solução. Após essa etapa, a solução foi titulada com tiossulfato de sódio e a porcentagem de cromo foi determinada. Pelo método da difenilcarbazida (ASTM D1687-1992), o cromo é determinado na forma de Cr6+ por espectrofotometria, através de uma curva padrão preparada com dicromato de potássio. Um volume de $50 \mathrm{~mL}$ da amostra teve seu $\mathrm{pH}$ corrigido com ácido fosfórico $5 \%$, e nesta solução foram adicionadas $2 \mathrm{~mL}$ de solução de difenil carbazida $(0,25 \mathrm{~g}$ de 1,5 - difenil carbazida em $100 \mathrm{~mL}$ de acetona) e $5 \mathrm{~mL}$ de ácido fosfórico $50 \%$. Após breve agitação da solução, a absorbância das amostras foram lidas e inseridas na equação da reta obtida pela curva padrão.

\section{RESULTADOS E DISCUSSÕES}

Os resultados da caracterização das amostras podem ser visualizados na Tabela 1 .

Tabela 1 - Caracterização das amostras de resíduo de couro, gelatina recuperada e retida e permeado.

\begin{tabular}{|c|c|c|c|c|c|c|}
\hline Amostra & $\begin{array}{c}\text { Umida } \\
\text { de }(\%)\end{array}$ & $\begin{array}{c}\text { Cinzas } \\
(\%)\end{array}$ & $\mathrm{pH}$ & $\begin{array}{c}\text { Condut. } \\
(\mathrm{mS} / \mathrm{cm} \\
\left.{ }^{2}\right)\end{array}$ & $\begin{array}{c}\text { NTK } \\
(\%)^{\mathbf{B}}\end{array}$ & $\begin{array}{c}\text { Teor de } \\
\text { Cromo }(\mathrm{mg} / \\
\mathrm{L})\end{array}$ \\
\hline Resíduo & 44,53 & 10,32 & 3,78 & - & 16,21 & $2,52^{\mathbf{A}}$ \\
\hline $\begin{array}{c}\text { Gelatina } \\
\text { recuperada }\end{array}$ & 97,73 & 0,357 & 7,73 & 6,26 & 12,25 & 0,22 \\
\hline $\begin{array}{c}\text { Gelatina } \\
\text { retida }\end{array}$ & 94,68 & 0,324 & 7,64 & 5,46 & 17,56 & 0,19 \\
\hline Permeado & 99,01 & 0,328 & 7,99 & 5,93 & 8,63 & 0,25 \\
\hline
\end{tabular}

A Teor de Cromo em \% (análise por titulometria); ${ }^{\mathrm{B}}$ em base seca.

Analisando os dados, a corrente de permeado apresentou um aumento nas variáveis teor de cromo, cinzas e condutividade comparado aos valores da gelatina retida nas membranas. O aumento no teor de cromo pode ser explicado pela passagem do sal pela membrana, já que o tamanho das suas moléculas são menores que os poros da membrana.

Os valores de condutividade e cinzas na corrente de permeado são maiores em comparação com a gelatina retida, pois o permeado possui maior concentração de sais. Ainda, 


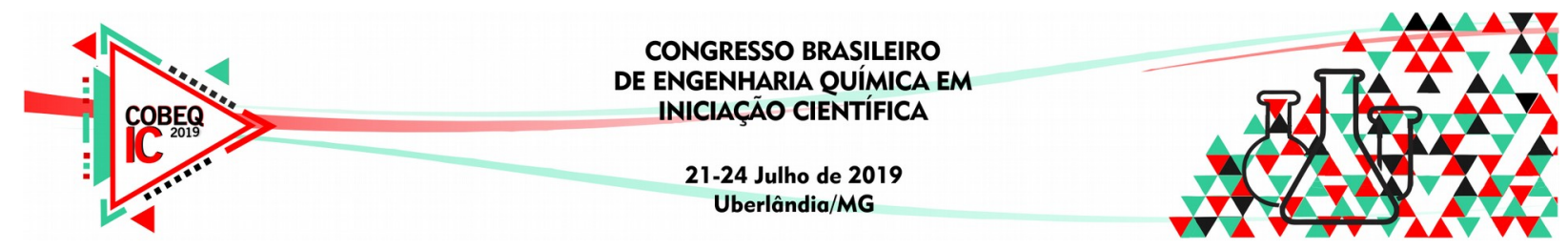

para a condutividade, uma alta quantidade de sal promove maior transporte de carga elétrica, devido à presença de elétrons livres (Cabeza et al., 1998).

Em relação ao NTK, houve um aumento no valor que se refere a gelatina retida quando comparada a gelatina extraída. Isso ocorre porque as moléculas de proteínas são maiores que os poros da membrana, logo, ficam retidas e acabam se concentrando na solução. É observado um valor de NTK para permeado, que é justificado pela passagem de aminoácidos, resultado da quebra das moléculas de proteína, que não fícam retidos pelas membranas (Dettmer et al., 2014; Scopel et al. 2018).

Quanto ao uso das membranas para filtração, pode-se elencar alguns problemas como as incrustações que a gelatina pode causar, levando a uma redução da vazão e consequentemente menor volume de coleta do permeado. A incrustação é causada pela deposição de componentes da solução que formam uma torta sobre os poros da membrana, bloqueando-os e impedindo a passagem da corrente (Romero-Dondiz et al., 2016).

\section{CONCLUSÕES}

Através dos dados obtidos, pode-se concluir que o uso de membranas de ultrafiltração auxiliaram no processo de remoção dos sais presentes na solução de gelatina e a concentração desta. Empregando esta operação, pode-se contornar o problema ambiental da disposição de resíduos de couro, agregando valor para este, através da sua reutilização como matéria-prima para extração da gelatina.

\section{REFERÊNCIAS}

ABNT. NBR 10004. Resíduos sólidos - Classificação 2004b, 2004.

ASTM. D3913: Standard Test Method for Acidity in Basic Chromium Tanning Liquors: 2015.

. D2807: Standard Test Method for Chromic Oxide in Leather (Perchloric Acid

Oxidation): 1993.

. D1687: Standard Test Methods for Chromium in Water: 1992.

. D2810: Standard Test Method for pH of Leather: 2013.

. D2617: Standard Test Method for Total Ash in Leather: 2012.

. D2868: Standard Test Method for Nitrogen Content (Kjeldahl) and Hide Substance

Content of Leather: 1996.

. D3790: Standard Test Method for Volatile Matter (Moisture) of Leather by Oven

Drying: 2012.

BRANDALISE, B.E. Obtenção e caracterização de filmes biodegradáveis de gelatina recuperada de resíduos de couro curtido ao cromo III com tratamento enzimático. Universidade de Caxias do Sul: Caxias do Sul, 2017. 


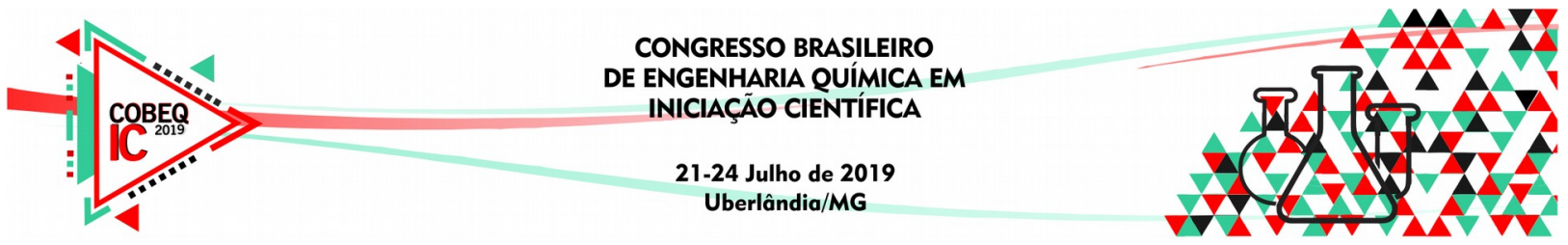

CABEZA, L. F.; TAYLOR, M. M.; DIMAIO, G. L.; BROWN, E.; MARMER, W.; CARRIÓ, R.; CELMA, P. J.; COT, J. Processing of leather waste: pilot scale studies on chrome shavings. Isolation of potentially valuable protein product and chromium. Wast. Manag., v. 18, p. 211 - 218, 1998.

CICB - Centro das industrias de curtume do Brasil. Exportando valor agregado: Dados. Disponível em: < http://www.cicb.org.br/cicb/dados-do-setor>. Acesso em 06 abr, 2019.

DETTMER, A.; SANTOS, R. M. O.; ANJOS, P. S.; GUTTERRES, M. Protein extraction from chromium tanned leather waste by Bacillus subtilis enzymes. $J$ of Asoci. Quím. Españ. de la Ind. del Cuero, v. 65, n. 3, p. 93 - 100, 2014.

FERNANDEZ, C. S. Obtenção de uma liga ferro-cromo por redução aluminotérmica de cinzas na incineração de resíduos de couro. Universidade Federal do Rio Grande do Sul: Porto Alegre, 2010.

GOMES, C. S. Otimização da operação de adsorção no tratamento de efluentes de tingimento de couro. Universidade Federal do Rio Grande do Sul: Porto Alegre, 2014.

SCOPEL, B.S.; RIBEIRO, M.E.; DETTMER, A.; BALDASSO, C. Cornstarch-Gelatin Films: Commercial Gelatin Versus Chromed Leather Waste Gelatin and Evaluation of Drying Conditions. J Polym Environ., v. 26, p. 1998-2006, 2018.

ROMERO-DONDIZ, E. M.; ALMAZÁN, J. E.; RAJAL, V. B.; CASTRO-VIDAURRE, E. F. Comparison of the performance of ultrafiltration and nanofiltration membranes for recovery and recycle of tannins in the leather industry. Journ. of Clean. Produc, v. 135, p. 71-79, 2016.

WANG, Y.; SHI, B. Concentration of gelatin solution with polyethersulfone ultrafiltration membranes. Food and Bioprod. Proces., v. 89, p. 163-169, 2011. 